\title{
Bangladesh Education Policy 2010: An Analysis of Its Contribution towards National Human Resources Development
}

* Md. Rashed Iqbal

** Dr. Amir Mohammad Nasrullah

Abstract

Bangladesh is an over populated country, yet its population can be converted to human resources for achieving economic growth. There are many elements for human resources development (HRD), among those education could be the most important element for developing human resources. Government could correctly identify that, if education system of Bangladesh could be reformed by an effective policy we can transform this demographic burden to dividend through HRD. In this note, Bangladesh Education Policy 2010 is considered to be one of the best education policy ever promulgated. But when we analyze its practical application, there are concern on its contribution towards NHRD including its implementation process in the field. Here, a well-orchestrated education policy can play key role for developing an adaptable workforce who can effectively contribute for building a prosperous nation.

Key words : National Education Policy, NHRD, Skill Development

\section{Introduction}

Policy is one of the principal vectors through which influence flows between the larger society and education institutions. When people speak of education policy, they refer to government decision rules regarding education, schools, colleges, or related matters (US Department of Education). The present National Education Policy was enacted 2010.The policy opened up a new era for Bangladesh Education System. Education policy in Bangladesh has always been an issue of discussion in the society. All the government from

*M Phil Researcher, Session 2014-15, ID 150059,Bangladesh University of Professionals, Dhaka, Bangladesh

** Professor of Public Administration, University of Chittagong, Chittagong,Bangladesh,amir.nasrullah@cu.ac.bd 
colonial era to the present day have tried to formulate an individual policy that reflected their own ideology and vision. Hence, from 1972 number of commission's reports were promulgated but none of those could reflect the promises and aspirations of the people. The Education Policy 2010 has the democratized notion in it, as it was circulated to all for comments and suggestion before the publication. The policy has the promise for reformation and development and displayed as the symbol of nations principle and conscience. But policy in paper is not enough to satisfy nation's aspirations which they are longing for. There are also hiccups in its application for NHRD which merits in-depth analysis. For reforming a policy social and contextual aspect should also be taken in consideration. Experts suggest that, during any education policy development, its curriculum and structure must be compatible with the contemporary development, whereas, its implementation depends on the will and ability of the government. In this note the educators often refer that, the education reforms in Bangladesh is often driven by the political apparatus of the government rather than by educators or bureaucrats and justifies as the basis of needs. Hence, in this paper the relevance of the education policy 2010 for NHRD will be studied to recommend its necessary modification for presenting a pragmatic education policy for Bangladesh.

\section{Objectives of the Study}

\section{Main Objective}

Main objective is to evaluate Bangladesh Education Policy 2010 for determining its contribution towards NHRD.

\section{Specific Objectives}

a. To study the Education Policy 2010.

b. To identify its linkage to NHRD.

c. To analyze the contribution of national education policy towards NHRD.

\section{Methodology Followed}

The methodology is based on the secondary data. Various books, journals, research reports, newspapers, etc are used as secondary 
sources of data. The present study is a narrative one, a thorough study of available secondary data was carried out to reach worthwhile conclusions and determine its relevance to NHRD.

\section{Key Concepts Defined}

\section{Education}

Education is the process of facilitating learning, or the acquisition of knowledge, skills, values, beliefs, and habits. Education can take place in formal or informal settings and any experience that has a formative effect on the way one thinks, feels, or acts may be considered educational. The main objective of education is to strengthen our mind so that we can perform better in the life. Education is important in life because it gives people the skills and tools they need to navigate the world. Without education, people would not be able to read, write, calculate or communicate; they would also not be able to perform jobs competently, accurately and safely. Education also teaches people about the world in which they live, including information about history, philosophy and culture (Shamsul,1965). However, many people believe that education is important in life for reasons beyond basic survival skills. Eleanor Roosevelt famously said that, education is essential to good citizenship and that education is important to life because it enables people to contribute to their community and their country. Education is important because it teaches people about the world around them. Education is also considered as the key to a nation's development. Education is the principal means to achieve the goal of poverty alleviation. Scholars believe education is important because it helps to answer life's big questions, including questions of how to live, work and love.

\section{Human Resources}

Human resources are the people who make up the work force of an organization, business or economy. "Human Capital is sometimes used synonymously with "human resources", although human capital typically refers to a more narrow view. Likewise, other terms sometimes used include "manpower", "talent", "labour", 
"personnel", or simply "people" (PPArya and BB Tandon, 1995).

\section{Human Resources Development}

HRD is a series of organized activities conducted within a specified time and designed to produce behavioral change of the human resources (Haslinda,2009). The origin of HRD was suggested to have started in the USA during the advent of the Industrial Revolution in 1800 s. But some writers argued that the roots of HRD emerged in 1913 when Ford Motor started training its workers to produce mass production in the assembly line. However, some scholars suggested that, during the outbreak of World War II, in the 1940's HRD emerged, as during this period workers were trained to produce warships, machinery, and other military equipment and armaments.

NHRD

NHRD deals with "government skill formation and employment policy, institutional development, partnership development with international agencies" (Metcalfe \& Reese, 2005, p. 456) .NHRD is considered as macro level HRD here macro HRD helps to develop educational opportunities, infrastructural development and enhance productivity of the people. Challenges of this level of HRD is to develop infrastructure for education and training at grassroots level, developing educational contents and syllabus under an effective education policy. Here inter-ministerial coordination is essential for preparing human resources planning for local vacancies and overseas employments.

\section{Policy}

The word policy is derived from the Greek polis, referring to city or citizen. Subsequent Roman usage led to the term polity, meaning government, government organization, regime, or nation. In modern parlance, policy refers to a uniform decision rule, a regulation, or a set of prescriptions that applies in all similar circumstances (US Department of Education). In short, any given policy represents the end result of a decision as to how best to achieve a specific objective (Torjman 2005,p.4). When people speak of education policy they usually refer to government decision rules regarding education, 
structures and stream of education schools or related matters. Benjamin Levin mentioned few points which are very important for understanding the education policy reforms, these are: Political consideration, History and culture, Institutions of the organization and government, constantly changing multi faced context. Education is intended to serve the social purposes, so idea about the education will change with the changing requirement of the society but very often the reforms are seen as the programmes of the educational change that are government directed and initiated based on political aspiration

\section{Relationship between Education and NHRD.}

\section{Education and NHRD}

There is a very strong relation between education and NHRD. A country should develop her people as an efficient workforce so that they contribute to the local and global market, which is very competitive as it ever. Education is essential for nearly every type of job or career, and in many cases, education makes the difference between being able to perform a job safely and accurately and being unable to perform a job at all. There is a continual need for enterprises to update much more regularly the skills mix of employees to respond to the opportunities or threats created by globalization and rapid technological change. Need based education is the only way to develop efficient human resources who can meet the challenges of globalization (Shamsuddoha $M$ and Hossain S Md. 2010). Nation should try their level best to give optimal education to its population through public and private educational institutions so that they can properly work at home and abroad. For countries that are both economically and socially developed such as Japan, education is no longer the main purpose of HRD because statistics show that $99 \%$ of the Japanese workforce is literate. Whereas for those that are only economically developing such as Bangladesh, HRD to be used as the principal tool for the development and implement organizational/governmental goals and objectives.

\section{NHRD and Education: Bangladesh Perspective}

$\mathrm{HRD}$ is at the core of Bangladesh's development efforts and access to 
quality education is critical to poverty alleviation and economic development. The Government is committed to undertake structural reforms that are expected to bring significant improvements in the education sector. Bangladesh's commitment to education has been clearly stated in its constitution and development plans with education being given the highest priority in the public sector investments. The 2017-18 budget has proposed an allocation of Tk.504.32 billion for education sector. The amount is 2.2 per cent of the GDP (gross domestic product) and 12.6 per cent of the total outlay. An allocation of Tk.284.10 billion has been allotted for the

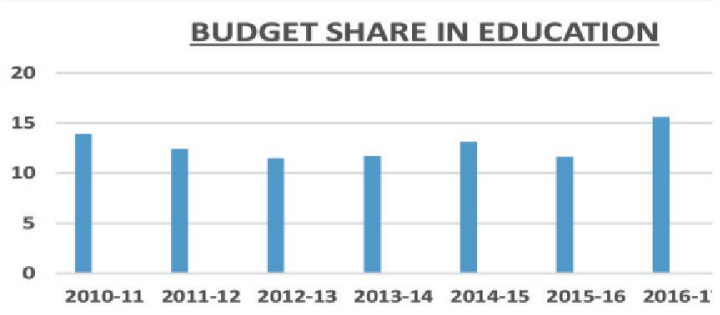

Figure 1: Last 8 years budget share in Education Sector (Source: Unnayan Anneshan,2017)

The education sector with an emphasis to secondary education is a priority area for the Bangladesh which plays significant role in overall development of Bangladesh. Education is considered a key strategy for effective HRD, poverty reduction, and socio-economic development, all which contribute to the national development. Government realizes that, there is a pressing need to develop a large part of the population into productive workers through the coordination and interaction between people, educational institutions, training programs, and technology where secondary education is regarded as the principal institutional mechanism for developing human skills and potentials ( $7^{\text {th }}$ Five Year Plan). But, having so much of focus on education, so far no significant action plan has been projected for such coordination. As such in the process 
of implementing her policy, actions like: development of new curriculum, resources allocation and education administration could not play any dominant role in integrating education with NHRD.

\section{Article 17 of the Constitution}

About education, article 17 of the constitution mentioned, the state shall adopt effective measures for the purpose of:

a. Establishing a uniform, mass-oriented and universal system of education and extending free and compulsory education to all children to such stage as may be determined by law.

b. Relating education to the needs of society and producing properly trained and motivated citizens to serve those needs; removing illiteracy within such time as may be determined by law.

\section{An Overview on the National Education Policy 2010}

\section{Background and Context}

24 September 1972, father of the nation Bangabandhu Sheikh Mujibur Rahman formed the 1st education commission that was Dr. Qudrat-e-Khuda Commission. The committee submitted its report on May 30, 1974. But after the assassination of the Father of the Nation Sheikh Mujibur Rahman the education policy was shelved forever and the country's education system continued to run with the centuries old ideas and infrastructure. Considering the national reality and the context, Awami League made the commitment in its election manifesto to adopt a national education policy in light with the Qudrat-e-Khuda Commission. Accordingly National Education Policy 2000 was adopted, but the following government did not implement the policy. Finally in April 6, 2009, 18 member committee was formed led by Professor Kabir Choaudhury to present the nation with an updated Education policy. The policy was finally passed in the Bangladesh National Parliament on December 7, 2010, and thus known as National Education Policy 2010

\section{Main Features of the National Education Policy 2010}

a. Objective Set. There are 30 aims, objectives, goals and principles mentioned in the Education Policy which include, among others : 
- To create a society free from the curse of illiteracy.

- To remove socio-economic discrimination in regards to race, religion and creed, and to eradicate gender disparity; to develop non-communalism, global fraternity, fellow-feeling and respect for human rights.

- To give priority to primary and secondary education; to show students the dignity of labour; to enable them to acquire skills in vocational education and facilitate self-employment, irrespective of educational qualifications.

- To ensure the proper context and situation in the education system at the higher level to facilitate the ideal environment for learning.

- To ensure the education of the physically and mentally challenged learners.

- To initiate a uniform curriculum in diverse types of schools delivering mandatory syllabus for some basic subjects to be taught in diverse types of schools.

\section{b. Glimpse on the Contents.}

- Pre-primary education for 5+ years children; employment of female teacher for pre-primary schools; Ensure teachinglearning process as an integrated method. Ensure teacherstudent ratio as 1:30; Inclusion of marginalized children; Establish library facilities in all primary schools.

- Policy suggested free, universal and compulsory primary education up to class eight and implement same curriculum and syllabus for all streams; the mandatory inclusion of the six compulsory subjects under all streams of educations namely general, madrasa, and technical. Class five students will have to sit for the public examination to mark the primary education as a uniform standard and teachers will have to be answerable. There will be no annual and scholarship examination at class five. Pre vocational education and scholarship to all education from class six to eight on the basis of examination. 
- Secondary education will be from class nine to twelve. All the student must study their own religion and receive morale education.

- Inclusion of the information technology and science in the curriculum is mandatory.

- Technical institution to be established up to Upazilla level. Modernization of the madrasa education to be done through inclusion of the information technology, and arrangement of text book and teachers for the indigenous children to enable them to learn in their own language.

- The policy suggested provision of free enrolment, free distribution of education materials, mid-day school meals, and stipend under special arrangement for bringing street children to school and continuation of the studies.

- Three years degree course to be replaced by four years honours course. In respect of higher education, decentralization of the National University by setting up centres in all divisions.

- The policy recommended a permanent education commission for the implementation of the policy.

\section{Analysis of the Present Policy on its Contribution towards NHRD.}

The national education Policy 2010 is considered as one of the most practical oriented policy ever formulated in Bangladesh. It is blended with the liberalism of the Qudrat-e-Khuda policy and aspiration of the forward looking citizens effectively. National Education Policy $2010^{\prime}$ tried to focus on development of human resources. It promises to develop learners with competencies so that he/she can be well accepted in the job market at home and compete for a decent position in global market. It also identifies the importance of imparting effective education at primary level thus preparing a strong foundation for quality secondary education. It highlights the need for mitigating discriminations among various secondary educational institutions and among various socio-economic, ethnic and socially 
backward groups; especially to support the advancement of education in the remote regions. The policy projected due importance to design, continue and implement a uniform curriculum and syllabus for the selected core subjects, irrespective of streams of the secondary education. Having included so much of positivity the bleak reality is after eight years if we ponder upon how much we could extract from this policy, we are yet to find enough to be contended.

a. Structures of Education System:. Inclusion of eight year primary education in light of the Dr Qudrat-e-Khuda commission is debatable. It is also rightly mentioned in the policy that, the challenges involved in extension are infrastructure development, recruitment of teachers and redesigning curriculum. Any policy formulation merits the consideration of social, historical contextual analysis. After forty eight years we cannot suddenly jump to raise our primary education to class eight. Integration of existing level of primary education with the next three classes of the old secondary level along with the arrangements for of competent teachers, poses greater challenge towards execution of new policy. In this scenario we cannot rule away the influence of political manifestation and egoistic notion as mentioned by Benjamin Levin in his book 'Reforming Education policy. In May 2016 education minister said, "In the National Education Policy-2010, there's a directive to extend the level of primary education up to class VIII from class V by 2018 , and now a process is underway to implement it." The logic behind the extension of the primary education as mentioned by the minister "Education up to class-eight will be the basic education for Bangladeshis. We want to ensure education for all up to this level so that the students can acquire skills and competence of a certain level. The move would reduce the risk of drop out". Here, the UNESCO prescription of 14 years of universal education also was a consideration for the government to extend the primary education upto class VIII. But on the other hand it is learned that, primary and mass education authority is not yet prepared to accept these additional responsibility. Under this prevailing bizarre situation between the implementing authorities -how much we are gaining from it? Finally a board was convened to study the feasibility of the 
extension of the primary education but we are yet to have a decision on it. But, there is no visible controversy over the proposal of extending the secondary education upto XII, as it is seemingly possible to implement with minor administrative adjustment and recruitment of teachers. Here, the problem is interrelated, since we are yet to make a decision on extension of primary education, we are not likely to extend secondary education upto XII soon. Meanwhile, we have passed eight long years to see the execution of the most coveted policy where we had the promise of having a pre vocational skill lesson from VI to VIII. The apprehension and dilemma from the stake holders at different level who would execute on ground, made the parents and the students skeptical about the whole policy, let alone the redesigning of the curriculum and inclusion of skill enhancement lesson.

b. Enlistment, Drop out and Unemployment: Bangladesh Bureau of Educational Information and Statistics (BANBEIS) revealed that, the dropout rate was 40.29 percent in 2015 , according to the report during 2016, the dropout rate among girls in secondary level was 42.19 percent and among boys was 33.80 percent. In 2015, the rates were 45.92 percent and 33.72 percent respectively, the report said. Meanwhile, the enrollment of students in secondary level in 2016 was 67.84 percent, of which girls were 73.10 percent and boys were 63.85 percent. Both dropout and enrollment rates for girls are higher than that of boys in secondary level, which suggests that boys are surviving better than girls. Meanwhile, in primary level, the dropout rate has lowered to 19.2 percent in 2016 from 20.4 percent in 2015. Again, the dropout rate in higher secondary level in 2016 was 20.08 percent, with 23.83 percent girls and 16.55 percent boys dropping out from studies. According to the same report, girls comprise of 51.9 percent of the total number of students in secondary level in Bangladesh, which is the highest among the E-9 countries. The other E-9 countries are Brazil, China, Egypt, India, Indonesia, Mexico, Nigeria and Pakistan. There are many reasons identified for the drop out of the students, among those the main reasons as identified by the experts are: High cost of education, lack of interest ,poor quality of education, and education return. 


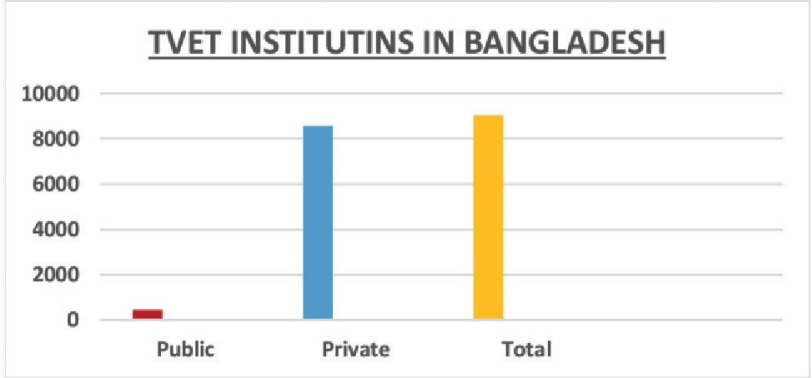

Figure 2: Comparison of the TVE institutions in Bangladesh

(Source: Unnayan Anneshan, 2017)

For a country like Bangladesh most of the parents calculates the cost of the education and its return which ultimately dictates the fate of the student .A study by Binayak Sen revealed that, the year of study and the income of an individual is endogenously co related because of the personal ability factor. A poor farmer of the remote area of the hill district will never engage his children for years in uncertainty of employment, rather he will be happy if the children could learn skills of saw mill work instead of studying at secondary level of school. The education policy 2010 highlighted in its objective for the skill development and creating employment opportunity but no clear guide line or mapping was done to materialize the objective. The number of vocational school is only 14 percent whereas the dropout rate is 45 percent. Hence, these technical and vocation education are not enough to play its role for the transformation of population to human resources. 
Table No 1: Number Institution and Enrolment in Vocational Institution

\begin{tabular}{|c|c|c|c|c|c|c|c|c|}
\hline \multirow[t]{2}{*}{ Types of Institution } & \multirow[t]{2}{*}{ Authority } & \multirow[t]{2}{*}{ No. of Inst. } & \multicolumn{3}{|c|}{ Teacher } & \multicolumn{3}{|c|}{ Enrolment } \\
\hline & & & Total & Female & $\begin{array}{c}\% \text { of } \\
\text { Female }\end{array}$ & Total & Girls & $\begin{array}{c}\% \text { of } \\
\text { Female }\end{array}$ \\
\hline \multirow[t]{3}{*}{ S S C Vocational } & Public & & & & & & & \\
\hline & Private & 2556 & 6667 & 1747 & 26.20 & 199718 & 50808 & 25.44 \\
\hline & Total & 2556 & 6667 & 1747 & 26.20 & 199718 & 50808 & 25.44 \\
\hline \multirow[t]{3}{*}{ HSC Vocational } & Public & 15 & 71 & 14 & 19.72 & 1255 & 764 & 60.88 \\
\hline & Private & 1078 & 48521 & 1122 & 23.12 & 1381.39 & 38414 & 27.81 \\
\hline & Total & 1093 & 4923 & 1136 & 23.08 & 139394 & 39178 & 28.11 \\
\hline \multirow[t]{3}{*}{ Authority } & Public & 15 & 71 & 14 & 19.72 & 1255 & 764 & 60.88 \\
\hline & Private & 3634 & 11519 & 2869 & 2491 & 337857 & 89222 & 26.41 \\
\hline & Total & 3649 & 11590 & 2883 & 24.87 & 339112 & 89986 & 26.54 \\
\hline
\end{tabular}


We need a strategy to integrate skill building curriculum with the general stream of the education. Government is treating stipend and free book as strategy for retaining the students. But the question remains what will happen to those highly educated students if they are unemployed? Rather, this sort of funding is complicating the situation further. Country like Finland does not provide vocational education to the students, on the contrary students are given skill building education as a part of general school curriculum as they could rightly identify that, technical and vocation education alone cannot play its role for the transformation of population to human resources. Education policy 2010 has correctly mentioned for the inclusion of pre-vocational education at primary level but no steps are taken as yet for the revision of the syllabus. A deliberate study on the need assessment and area wise mapping is required for the skill development and higher study planning for the students.

c. Work Force Planning and Skill Development Investment: All Strategy development demands an achievable policy end state. Unfortunately we have not done a workforce mapping for our future requirement. Education policy do not focus our work force need for fulfilling vision 2021 or even for vision 2041. We do not know, what proportion of our presently enrolled student need to enter work force after ten years? What proportion of students should go for higher studies? or, who all need technical or vocational education? Do we have any plan for diverting different streams of students to their destined institution within a prescribed time frame? Possibly not. We need to invest heavily on education and that investment should be based on education return analysis, otherwise whatever money we are investing on education will be mostly wasted in vain.

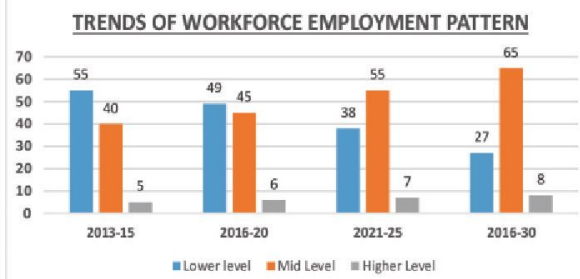

Figure 3: Trends of Workforce Employment Trend in Bangladesh (Source: Rafique 2017) 
d. Public Examination: Extension of universal and compulsory primary education up to class VIII could not be implemented yet due to lack of infrastructure. Again the process is made further complicated by introducing Primary Education Completion Examination (PECE) after grade five and Junior School Certificate exam after class eight. From the very beginning experts had been apprehending that sitting for a public exam at the age of eleven or twelve may suffer from mental pressure and these exam may promote an unhealthy competition among the young learners. Education experts, researchers, intelligent citizens, teachers and guardians have questioned the value of these examinations. It does not contribute to improving the teaching learning process. Many expert said, the effects of PECE have been to encourage drills and rote memorization, neglect understanding and creativity, disregard basic content of the curriculum, and discourage thinking and reasoning. The educationist remarked in different forum that, given the scenario it is difficult to understand how we can have a congenial stress free learning environment for acquiring basic knowledge for our children who would become the asset for our national development in future.

e. Teachers Ratio.: In all the educational institution the number of the students have increased many folds but the teachers are not recruited in the same ratio. Most of the cases teachers do not teach the particular subject for which he or she has been appointed. The MPO (Monthly Pay order) rule, influence of the local leader including governing committee, irregularities of the recruiting are possible main reasons for not having the qualified teacher for particular subject. Again, due to shortage of teachers, one teacher has to take care of other subjects for which he or she is not been appointed.

f. Private Tutor and Coaching.: It seems nothing can stop the dominance of coaching and tutor business. Lack of quality class room teaching and influence of unethical teachers compels guardian to send students for coaching. In our country very few parents can teach their children at home, consequently parent rely heavily on tutor or coaching as student are not prepared well in the class. Those who can afford to send children for coaching is somehow managing their 
students learning, but how about those who cannot afford to spend money for coaching? A disparity and inequality seems to dominate the existing society and thereby posing a severe effect on child psychology and their grooming up process.

g. Tertiary Level of Education: The influence of politics is more acute in the tertiary level of institution. No one is against the healthy student politics but in the name of politics very often students are being used as pawn of the dirty political game. Teacher's recruitment, student's admission, allocation of dormitory or even heinous activities like collection of ransom or drug dealing are often observed in the tertiary level of institution. A well thought of policy direction followed by a sound implementation strategy with the support of legal framework remained as a long cherished dream for the innocent student parents and teachers. In the tertiary level education national university is seriously compromising the standard of the education. Lack of supervision, poor quality of education are resulting in a good number of poorly equipped graduates in the work force of the country. The decentralization of the national university could further aggravate the situation, as such immediate control of these situation to be initiated trough a special commission to suggest policy reform and ensure quality education at tertiary level.

h. Teachers Training: There is no alternative to gaining excellence other than training and education. The modern pedagogy is dynamic, it merits an up gradation of the personal and institutional approach with the changing socio-economic and technological scenario. Quality of education much depends on the quality of teachers. Teacher should be trained according to the requirement of the curricular and the student's needs. Policy guideline should specify the timely development of the teachers through various skill building programs as they grow teaching experience. Teacher's remuneration and incentives along with the promotion prospects to be linked with the skill development and qualification attainment in each level of teaching.

j. Teaching as a Career: If we want to attract brilliant graduates for the teaching we have to make this career an attractive 
one. Good salary, job security, scope for higher study along with a social campaign for attracting promising youth for teaching profession to be carried out. Teachers to be kept out of local politics and external influence. Recognition of the best teachers programme with attractive reward to be carried out in each school, upazila ,district and at national level for the retention of the sincere and qualified teachers. Government to take strict measures to keep teachers recruitment process free and fair. A strict supervision on the observance of code of conduct for the teacher and governing body to be ensured through a neutral yet competent executive body at district level.

k. Education Administration and Coordination: Education administration often seen as the main bottle neck in implementation of the policy at ground level. Inter-ministerial coordination, synchronized activity within directorate, district education officials and institutions to be ensured through an efficient procedure under workable policy direction.

1. Curriculum and Core Subjects: Uniform education system is a constitutional obligation for the formulation of education policy. The National Education Policy 2010 recommended teaching of common core subjects like Mathematics, Science, Bangladesh Studies, Environment and Climate Change in all streams at the primary level, including general, English medium, technical schools and madrasas. But it is yet to be fully implemented in English medium schools and Alia madrasa. Kowmi madrasa is even yet to except it in their curriculum. If we want to develop human resources under a common strategy it is imperative to ensure uniform curriculum at all streams of education.

m. Implementation Committee: National Education Policy 2010 has many positive ingredients for human development in Bangladesh but the policy implementation is very slow in progress. An independent and effective policy implementation committee to be formulated immediately for supervising the implementation process and advice ministry on its progress and challenges accordingly. 


\section{Conclusion}

The population density in Bangladesh is one of the highest in the world today. Further, less and poorly skilled population are the major constraints for achieving economic growth for the country. It is evident that, with the present trend, job market will not be able to create sufficient opportunity for jobs seekers due to insignificant supply of skilled manpower in the market. In this backdrop the study tried to highlight the relevance of the education policy 2010 towards human resources development. The demographic pattern and its forecast for next 30 years indicates us to invest prudently for its heavy working age population, this situation may not prevail after fifty years or so. In this context it is imperative of us to understand the importance of HRD and reform education policy to initiate a sustainable work force development strategy for fulfilling the dream of 'Developed Bangladesh'.

\section{Recommendations}

In light of the study on the contents of the education policy following recommendations may be considered for education policy reform in order to foster HRD in Bangladesh.

- Allocation of the education budget to be increased substantially for ensuring quality education. It should be immediately raised to at least $4 \%$ of the GDP.

- Government should formulate a neutral and effective education policy implementation committee to execute the implementation process smoothly.

- All district to have a competent and powerful education monitoring and coordinating committee to ensure quality education at district level.

- Government to take necessary steps to attract brilliant graduate to choose teaching profession and ensure a free and fair recruiting procedure for their recruitment.

- Education policy to include work force mapping for introducing a skill building strategy for the students.

- Uniform curriculum to be enforced to ensure common focus on 
the HRD in Bangladesh.

- Government should provide best support to increase enrolment and decrease dropout by ensuring joyful, meaningful and quality education.

\section{References}

Ahmed, $\mathbf{M}$ and, Williams J, (2008) 'Education Priorities for Human Resource Centered Development in Bangladesh'

Ahmed, M. (2014) Draft on EFA2015 National Review-Bangladesh.

Ahmed, S. (2010) 'Dropout Rate in Secondary Level Education in Bangladesh' The University Press limited, Dhaka.

Andaleev S. (2011) Education and National Development, The University Press Limited, Dhaka.

Arya. PP and TANDON. BB (1995 ), 'Human Resources Development, concept and issues', Deep and Deep publications.

Asian Development Bank (2001). Education and National Development in Asia. Asian Development Bank. Manila.

Billah, A.M (2009), Education Policy A Critical Review', Bangladesh Education Article,

Francis, K. (1993) 'Education and Development Challenge', Discovery publishing house, New Delhi.

Government of the People's Republic of Bangladesh. Education for All, National Plan of Action (1995), Annual Reports (Primary and Mass Education Division). Dhaka, Bangladesh.

Graham, B. (1991),'Education in the Developing World', Longman Publishing, UK.

Haslinda, A (2009), Evolving terms of Human Resource Management and Development, University Putra Malaysia The Journal of International Social Research, Vol 2/9.

Huq, K,(2010) Human Development Challenges in South Asia', Published online: SouthAsian journal of Human Development 1;1,71-82.

Huq, M Shamsul (1965) Education and Development Strategy in South and South east Asia, East West entre Press, Honolulu.

Huq, M. (1983) Higher education and employment in Bangladesh, The University Press Limited, Dhaka.

Huq, M. (1995) Human Development Paradigm, The Development Economics Reader, Chapter 2, Secondi, S. Rutledge, London.

Huq, M. (1995) Reflections of Human Development. Oxford University 
Press, Amazon.com.

Huq, S. (2012), Is the Present Education policy Adequate for Countering terrorism, Religious and Ethnic Tolerance? Springer International Publication, South Asia Democratic Forum (SADF), Belgium.

Levin, B. (2001),'Reforming Education', Routledge / Falmar publications, London and New York.

Mannan, A. (2017)'A degree may not be enough, "Daily Sun, 8 July 2017.

Metcalfe. B DAWN and Rees, Theorizing Advances in International Human Resource Development, Human Resource Development International, Vol. 8, No. 4, 449-465, December 2005

Ministry of Education, Bangladesh Education Policy 2010.

Ministry of Planning, 7 th five year plan.

Ministry of Primary and Mass Education (MoPME) and support from UNESCO. Dhaka.

Rafique, A.(2017) Build Skill Bangladesh for Emerging Bangladesh as Developed nation, Joint publication by IDEB AND BTEB.

Shamsuddoha. M and Hossain. Shahadat M, Globalization compliant and HRD focused Education in Bangladesh: A Futuristic Policy Discussion, Journal of Chittagong University Social Science Studies, Vol. 42, 2010.

Torjman, S. (2005), What is policy, Institution of Social Policy, Ontario, Canada.

UNDP, Human Development Report published in 1990.

US Department of Education, Education Reform in United States. https://www2.ed.gov/a 